\title{
Bentonite clay suspension -coagulation process and identification of properties
}

\author{
Piotr Warzecha ${ }^{1, *}$, Bartłomiej Hilger ${ }^{1}$, and Stawomir Różycki ${ }^{1}$ \\ ${ }^{1}$ AGH University of Science and Technology, Faculty of Mechanical Engineering and Robotics, \\ Department of Power Systems and Environmental Protection, Mickiewicza 30, 30 - 059 Kraków, \\ Poland
}

\begin{abstract}
The main aim of the research presented in this paper is study of volume coagulation of bentonite suspension. Investigation of physical properties included measurement of particle size distribution, chemical and phase analysis of prepared suspension, as well as preparation of sedimentation test graph and determination of dependence between concentration of the suspension and turbidity of the suspension. Relationship between coagulant dose and concentration was also determined during this analysis. This research could help in determination of critical coagulation concentration duringanalysis of coagulation process. Also it could be used duringsimulations of distribution of suspension in high - performance sedimentation settling tanks for suspension of similar origin in water treatment process.
\end{abstract}

\section{Introduction}

This paper presents the results of volume coagulation of bentonite suspension study. The aim of this article was to identify properties of prepared suspension: particle size distribution, chemical and phase composition. Additionally graphs of critical coagulation concentration and sedimentation, and also the relationship between suspension concentration and turbidity were prepared. Dependence between concentration of suspension and critical coagulant concentration has also been determined, which may help to find out the critical coagulant concentration for the coagulation process or it can help during the process of designing high efficiency sedimentation tanks in water treatment plants for suspensions of similar origin.

The main source of water used in water treatment plants in Poland are surface waters [1]. Water resources for economic purposes are sometimes inadequate, so it is important to modernize existing water treatment plants and create new ones. The acquisition and purification of potable water is one of the problems faced by water treatment plants, due to strict standards of quality for potable water [2]. Existing technologies of water purification are designed to remove the solid phase (various types of minerals and organic substances such as clay or humus), which causes the colour and turbidity of the water. The solid phase causing the turbidity may pose a threat to public health and technical infrastructure.

*Corresponding author: piotr.warzecha@agh.edu.pl 
Reduction of the solid phase pollutants in water is essential not only for aesthetic reasons, but also due to fact, that the surface of particles of the solid phase can be inhabited by microorganisms and bacteria that are harmful to human health [3]. Pollutants of surface water can originate from various places [4], they can be washed out of fields and floodplains during rains or storms and can be carried by wind from further areas.

In order to remove solid phase from water, various separation techniques can be used. One of those techniques is the sedimentation process often assisted by multiflux lamella packets in order to intensify the separation process [5] and also by the means of coagulation or flocculation process $[6,7]$ which allow the solid-phase particles to aggregate into larger flocs $[8,9]$ and thus produce clear water without the solid phase.

The purpose of the study presented in this paper was to determine the influence of suspension concentration before the coagulation process on the critical coagulation concentration. Concentration of suspension is a parameter that is used often in determining other indicators characterizing properties of suspensions such as sedimentation rate or efficiency [10], turbidity [11], and for flow processes modelling [12].

\section{Laboratory studies - preparations}

The representative suspension subjected to the coagulation process to determine the critical coagulation concentration was a suspension prepared from sample of Slovakian bentonite, which can be one of contaminants from areas where water is abstracted as a source water used in processes in a water treatment plant. Two types of coagulants were used. Both are commonly used in water treatment plants. One of them was PAX 19XL from KEMIPOL, which is an aluminium-based coagulant. It is characterized by low turbidity and has a gray coloration - it is attractive for organoleptic reasons - the emerging flocs are whitish and do not increase turbidity too much. That is why it is widely used for the treatment of drinking water and the treatment of municipal and industrial waste water. The second coagulant was PIX 116 from KEMIRA, an iron-based coagulant, which has the ability to precipitate and remove phosphorus, hydrogen sulphide and it is used in waste water conditioning and water treatment processes.

The efficiency of the sedimentation process on the reduction of pollution was determined in the laboratory using the sedimentation test. The static sedimentation test was carried out in accordance with the Polish standard PN-G-04570 [13]. A prepared suspension with a specific volume was poured into a cylindrical tube used in the static sedimentation test [11]. The sedimentation tube was set at a 60 degree angle to the ground [14], and after stirring the contents of the tube, the height of separation point between the clarified suspension and sedimenting suspension was determined. The turbidity study was carried out with two apparatuses, by the means of measurement of the intensity of light diffused on solid particles. One of them - Turbidirect from Lovibond, enables a turbidity measurement using a visible light source. The second turbidimeter was the WTW TURB 555 IR turbidity meter. The light beam in this device is generated by a diode emitting infrared radiation. Measurement of the particle size distribution of the bentonite suspension was carried out using a Malvern Mastersizer 2000E laser diffractometer equipped with the original Hydro MU wet sample dispersion unit. The chemical composition of the bentonite was determined by the XRF method using the Philips PW1404 spectrometer as well as with the FEI QUanta 250 FEG SEM. The SEM images were also made with the same device. Phase analysis was done with Philips APD X'pert PW 3020. Zeta potential was obtained with the use of Nanosizer-ZS - Malvern Instruments.

The bentonite suspension was prepared as follows: $500 \mathrm{~g}$ of fine bentonite sample was mixed with water $\left(4 \mathrm{dm}^{3}\right)$ in 5 litre container. After mixing the suspension for homogenization, the obtained suspension was sieved through a $320 \mu \mathrm{m}$ sieve to produce 
a suspension used for the study. The next step was to determine the concentration of the prepared suspension using a filtering method. The suspension concentration determined by this method was $22.4 \mathrm{~kg} / \mathrm{m}^{3}$. Before each test the suspension was mixed again to return it to the starting point, then it was immediately poured into a measuring dish.

For the turbidity test, concentration of the suspension depending from the initial turbidity was determined using a Turbidirect turbidimeter. Points of concentrations were assumed to be the most common turbidity in water treatment facilities. Turbidity at water treatment stations during the station's annual operating period ranges from NTU 5 to even up to NTU 800 (in rare cases). Turbidity distribution were measured for different concentration of prepared bentonite suspension, the results of this procedure are presented on Figure 1. Then a single suspension dose was determined to achieve the desired turbidity in order to conduct critical concentration tests. Measurements were verified several times to avoid errors of measuring the volume of the bentonite suspension.

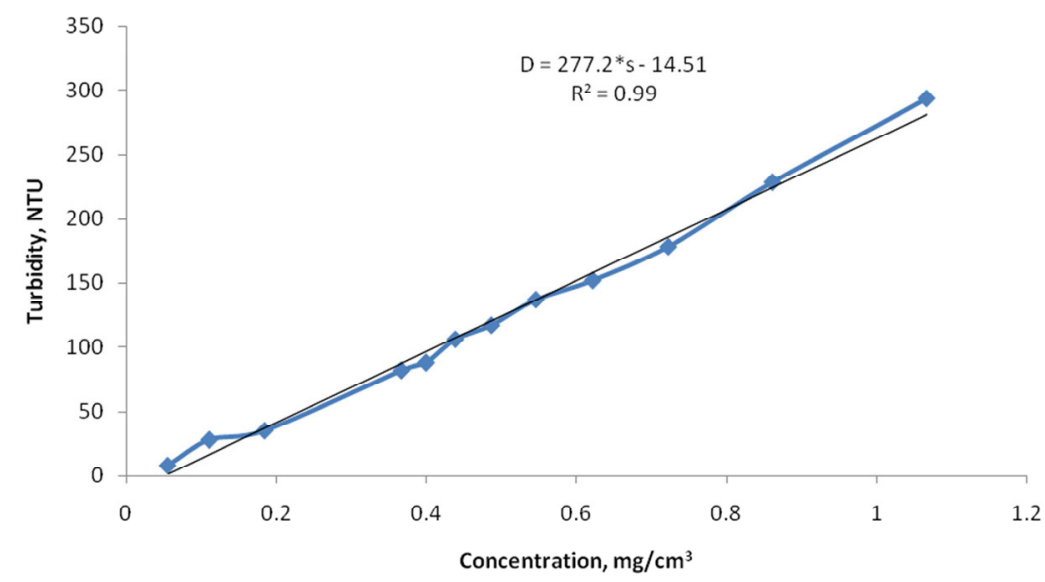

Fig. 1. Influence of concentration of suspension under investigation for turbidity- measurement with visible light (solid line indicate function of linear regression, D - dose of bentonite suspension, $\mathrm{s}$ - concentration).

On the basis of its turbidity, using a well-known engineering dependence, (1) preliminary critical coagulation concentration for each suspension concentration was determined [15]:

$$
D=7 * \sqrt{T}
$$

where:

$T$ - turbidity of suspension, NTU;

$D$ - preliminary coagulation concentration, ppm.

It is important to notice that turbidity has a strong connotation with concentration of suspension, and that, this dependence can be linear, as it was in this case. Turbidity can be an attractive alternative to determining the concentration of the suspension for suspensions with low concentration. In addition, the turbidity index itself is associated with aesthetic and organoleptic characteristics of water. Turbidity also has another advantage, i.e. it can be quickly determined and the sample is not consumed by the process (e.g. in contrast to gravimetric analysis).

Determination of critical coagulation concentration for analyzed bentonite suspension was made by jar-test (experimental coagulation analyzed for five different coagulant doses determined from the turbidity of the suspension). From the preliminary coagulation concentration (obtained from the formula(1)) two higher and two lower doses of coagulant 
were assumpted to determine the critical coagulation concentration for each coagulant. For each coagulant dose, a complete coagulation process was performed and a plot between the final product quality (turbidity) and a coagulation dose were obtained.

Five beakers of capacity of $0.6 \mathrm{dm}^{3}$ were filled with the required volume of suspension to obtain desired concentration of suspension (in order to have a series of samples with the same turbidity). In the next step, the prepared samples were filled with water to a volume of $0.5 \mathrm{dm}^{3}$. The sample then was placed in a stirrer, where continuous mixing of the suspension was carried out (the number of revolutions of the high speed stirrer was $600 \mathrm{rpm}$ ). A suitable amount of coagulant or mixture of coagulants was then dosed, and after 60 seconds of fast mixing with the same speed, the speed of the stirrer was reduced to $20 \mathrm{rpm}$ for 20 minutes in order to continue the process of coagulation during slow mixing and to allow the solid phase to aggregate into bigger flocs.

After stopping the process of slow mixing the beaker with coagulated suspension was removed from the stirrer and then it was left still for 5 minutes. After that time, turbidity of decanted water above the precipitate was measured. The procedure was repeated for subsequent doses of different coagulants.

\section{Results and discussion}

The results of the study on the effect of bentonite suspension concentration on turbidity are presented in Fig. 1. It shows a linear trend between these correlations across the range of the measurement. The determined equation and the value of the determinant factor determine a good fit of the model to the obtained results from laboratory tests ( $\mathrm{R}^{2}$ coefficient) of 0.99 .

On the basis of the sedimentation test shown in Figure 2, velocity of the suspension has been determined. The value of velocity was determined with the use of the equation (2):

$$
v z=\frac{\Delta h}{\Delta t}
$$

where:

$\Delta \mathrm{h}$ is the increment of height (descending layer of separation),

$\Delta \mathrm{T}$ is the time interval in which this increase occurred.

The velocity of the suspensions obtained during test are as follows:

- Suspension: $\mathrm{vZ}=0,92 \mathrm{~mm} / \mathrm{s}$;

- Suspension + PIX: vz=2,52 mm/s;

- Suspension + PAX: vz=2,69 mm/s.

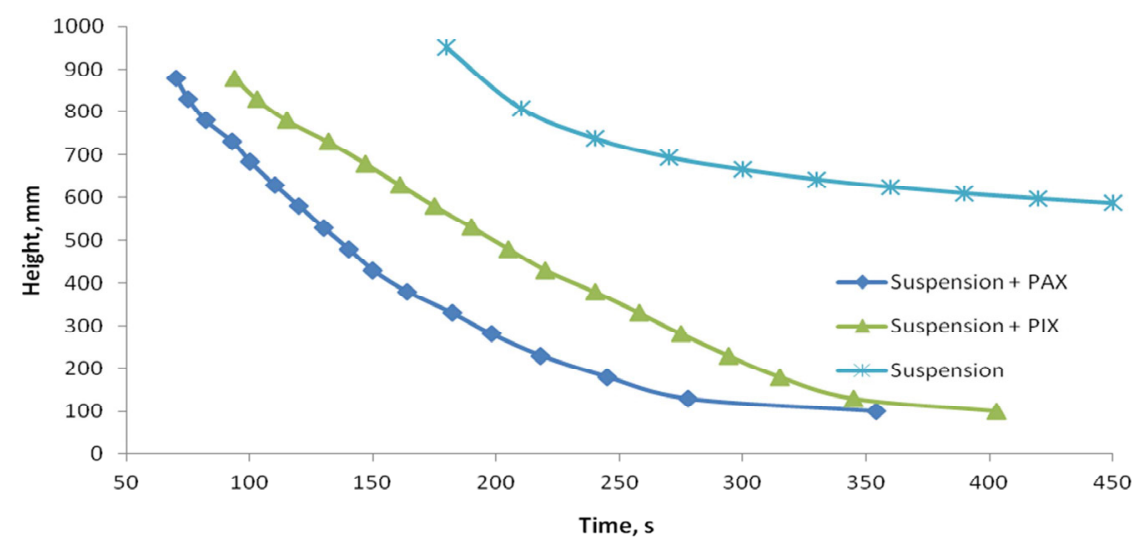

Fig. 2. Sedimentation test of the bentonite suspension. 
The conducted research clearly showed a significant effect of coagulants on the rate of sedimentation of bentonite suspension. In this case aluminum coagulant PAX, had a little more effect on the velocity of the sedimenting flocs $(\mathrm{vZ}=2.69 \mathrm{~mm} / \mathrm{s}$ for PAX coagulant) than the PIX coagulant (velocity of the sedimenting flocs: $\mathrm{vZ}=2.52 \mathrm{~mm} / \mathrm{s}$.)

Results of particle size distribution measurements are shown in Table 1 and Figure 3. The tested suspension is medium and fine-grained suspension - most grains (about 90\%) are in the range between $1 \mu \mathrm{m}$ and $60 \mu \mathrm{m}$, while the modal value is approximately $26 \mu \mathrm{m}$, which puts this suspension as fine-grained. The SEM image (Figure 4) show a convergence with the data obtained from grain size measurements. It is also noteworthy that the grains are not spherical - they are more elongated and compacted aggregates, which under the influence of ultrasound ( $20 \mathrm{kHz}$ for 3 minutes), are broken up into smaller particles (Figure 4) - the modal value in this case was about $9 \mu \mathrm{m}$, whereas most grains are less than $41 \mu \mathrm{m}$, which also qualifies the suspension as fine grained. The composition remains monomodal in character. The content of clay minerals such as montmorillonite or illite and their specific structure (structure which looks like tiles or plates) and agglomerates can also be seen in the shown SEM image (Figure 4).

Table 1. Particle size distribution - statistical parameters.

\begin{tabular}{|c|c|c|}
\hline Parameter, $\boldsymbol{\mu m}$ & Without sonification & With sonification \\
\hline Median - D50 & 16.93 & 9.61 \\
\hline Mode & 26.33 & 8.72 \\
\hline D10 & 3.04 & 2.48 \\
\hline D90 & 59.50 & 40.90 \\
\hline
\end{tabular}

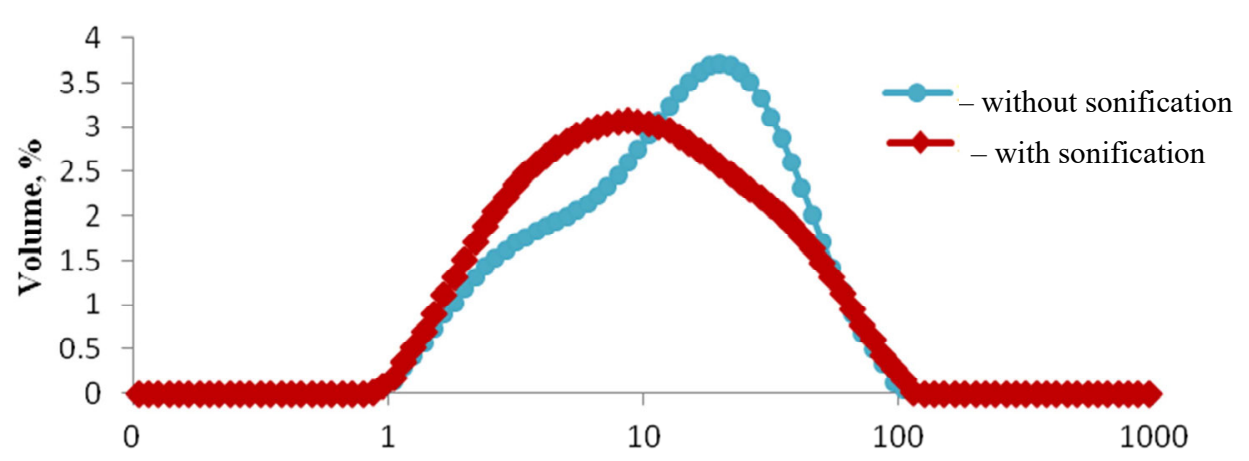

Particle size, $\mu \mathrm{m}$

Fig. 3. Particle size distribution of the suspension under investigation.
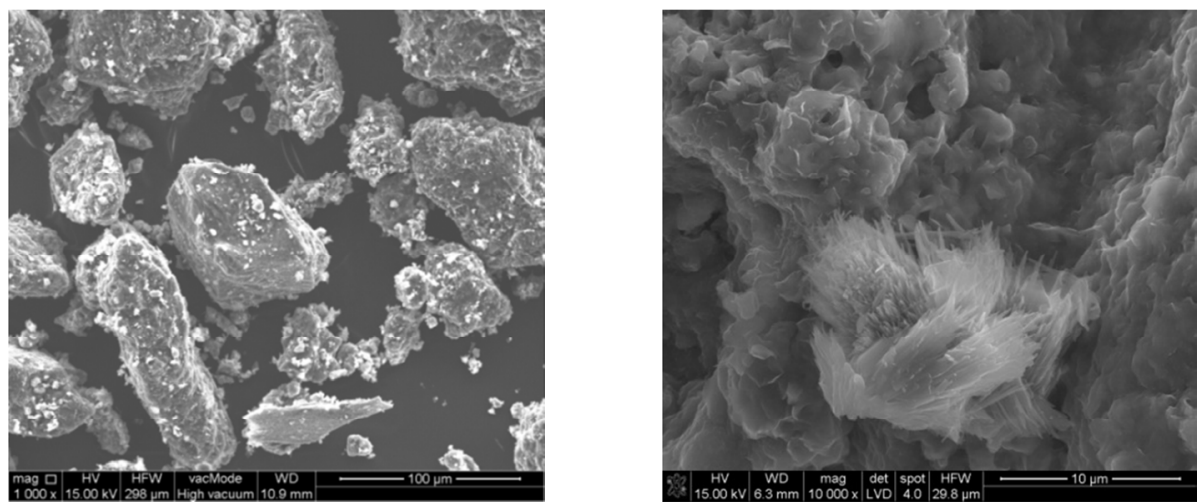

Fig. 4. SEM images of bentonite under consideration. 
The results of chemical and phase analysis are presented in Table 2 and on Figure 5, and reveal that silicon is the dominant element with the highest content, also aluminium is present in analysed material. Calcium, iron, potassium and magnesium were additionally found in the sample. The other elements are present in amounts lower than $1 \%$.

Table 2. Chemical and phase composition (crosses indicate the amount of identified phases).

\begin{tabular}{|l|c|c|c|}
\hline \multicolumn{2}{|c|}{ Chemical composition, \% } & \multicolumn{2}{c|}{ Phase composition } \\
\cline { 1 - 2 } $\mathrm{MgO}$ & 1.543 & \multirow{2}{*}{ Montmorillonite } & + \\
\hline $\mathrm{Al}_{2} \mathrm{O}_{3}$ & 21.103 & & + \\
\hline $\mathrm{SiO}_{2}$ & 71.960 & Illite & + \\
\hline $\mathrm{K}_{2} \mathrm{O}$ & 1.112 & Cristobalite & +++ \\
\hline $\mathrm{CaO}$ & 1.422 & & + \\
\hline $\mathrm{Fe}_{2} \mathrm{O}_{3}$ & 2.860 & & \\
\hline
\end{tabular}

The results of the chemical analysis presented were confirmed in the phase composition of the investigated bentonite (Figure 5). These compounds form minerals from the group of clay minerals:

- Montmorillonite: $(((\mathrm{Na}, \mathrm{Ca}) 0,3(\mathrm{Al}, \mathrm{Mg}) 2 \mathrm{Si} 4 \mathrm{O} 10(\mathrm{OH}) 2 \bullet \mathrm{n}(\mathrm{H} 2 \mathrm{O}))$

- llite: ((K,H3O)(Al,Mg,Fe)2(Si,Al)4O10[(OH)2,(H2O)]),

which are present in the bentonite under investigation. The main component of this bentonite was Sillica $\mathrm{SiO}_{2}$ in cristobalite form. The phase composition of the samples was verified by means of SEM/EDX, as can be seen on Figure 4 (Figure on the right shows typical Montmorillonite/Illite mineral type shape).

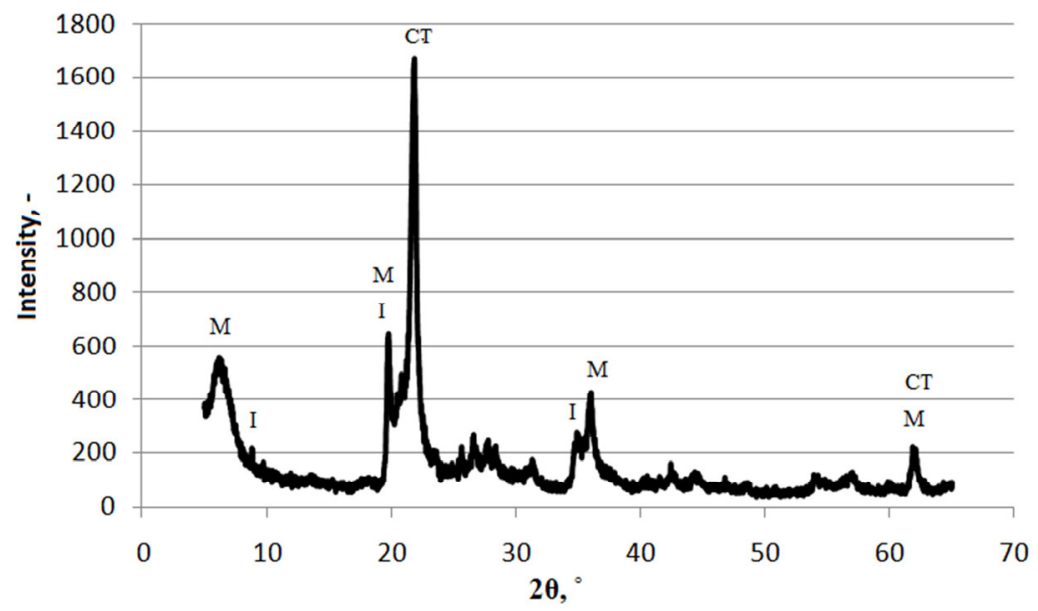

Fig. 5. XRD Analysis.

On Figure 6 zeta potential chart is presented. Zeta potential is the value of the surface charge of particles. It shows that in the wide range of $\mathrm{pH}(3-12)$ of untreated suspension zeta potential stays at almost the same level - about $-33 \mathrm{mV}$. Zeta potential is drastically lowered between 1 and $3 \mathrm{pH}$, and also it is higher past $12 \mathrm{pH}$. At the beginning of measuring the zeta potential the $\mathrm{pH}$ of bentonite was at about 5.1-5.8. Thusthe coagulation process of such suspension is needed, in order to lower the zeta potential to allow for quicker aggregation of particles. 


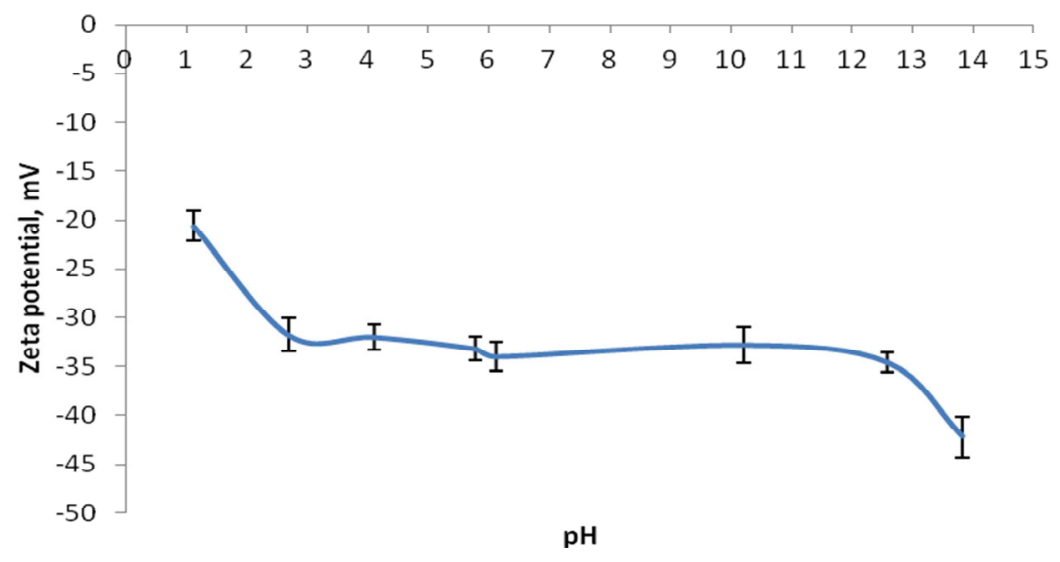

Fig. 6. Zeta potential.

Figures 7 and 8 show the results of the coagulation process: the relationship between the amount of critical coagulation concentration and the concentration of the bentonite suspension. The influence of the suspension concentration on critical coagulation concentration of the iron-based (PIX) and aluminium-based coagulant (PAX) is presented. The increase of the suspension concentration entails the increased dose of coagulants. The trend lines shown in Fig. 7 and Fig. 8 showed logarithmic regression for both coagulants with a high value of $\mathrm{R}^{2}$ (above 0.94 ). The best sedimentation efficiency was obtained using PIX coagulant for suspension concentrations between $(0.15$ to $0.5 \mathrm{~g} / \mathrm{l})$. The bigger scatter of the points for low values of concentration (turbidity) stems from adopted methods of measurement. This kind of measuring method can yield measurement errors, but on the other hand the filtering method might be time consuming and even impossible to conduct (mass of the precipitate is a lot smaller then the mass of the filter).

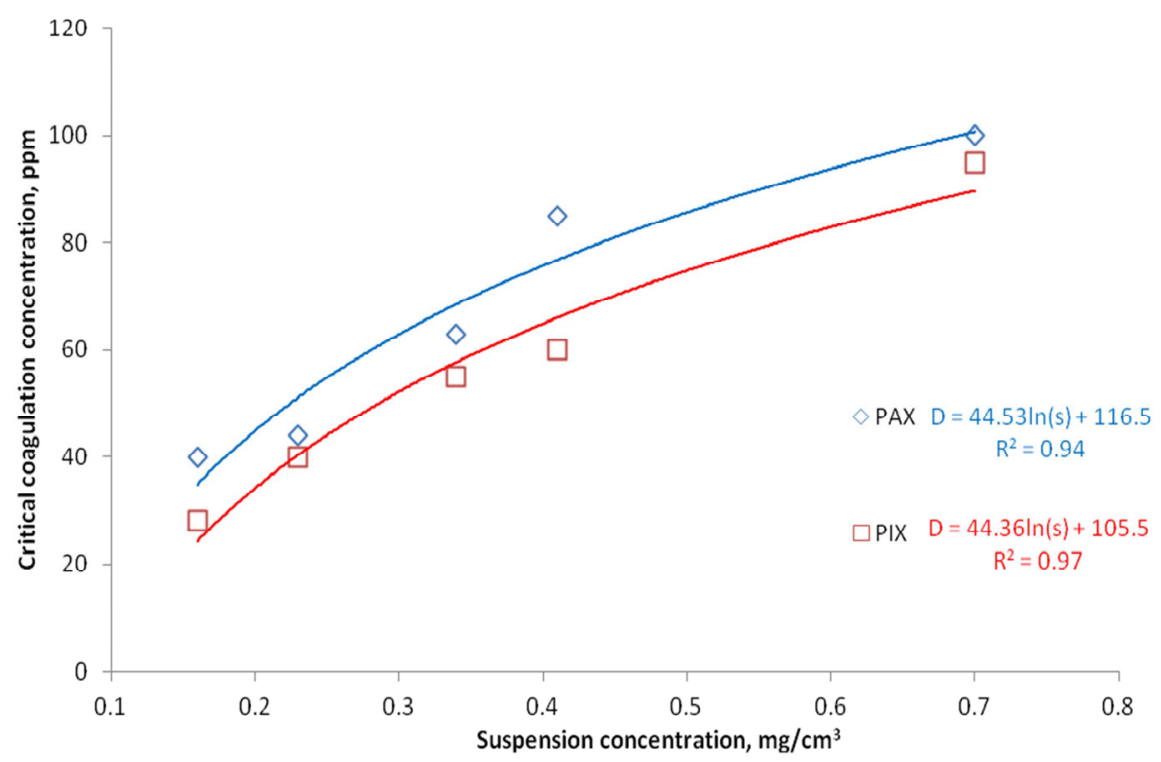

Fig. 7. Relationship of coagulant dose and concentration - measurement with visible light (D - dose, $\mathrm{s}-$ concentration). 


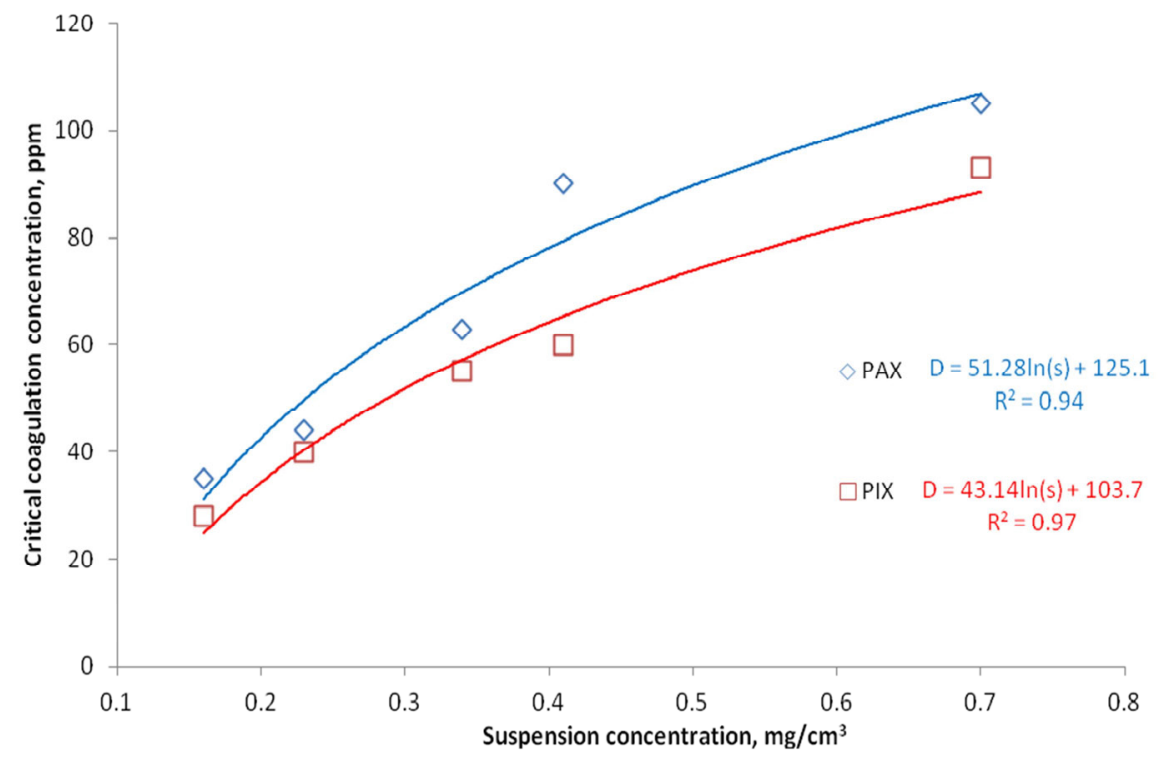

Fig. 8. Relationship of coagulant dose and concentration - measurement with infrared light ( D - dose, $\mathrm{s}$ - concentration).

It is important to notice that PAX coagulant has the best effect on the velocity of the sedimenting particles (Figure 2), but it has its costs - in order to obtain similar effects it is necessary to use larger amounts of the PAX coagulant than the PIX coagulant.

\section{Conclusions}

One of the typical processes used to remove mainly various impurities is the coagulation process. It is extremely useful when there is a need to remove small solid phase (those that have colloidal sizes, basically smaller than 1 micrometer) of organic and inorganic origin from water. A properly running coagulation process not only ensures high efficiency of sedimentation (phase separation), but also the removal of solid pollution from water. The effects of effective phase separation are: reduction of suspension turbidity, indicators of organic pollution, colour intensity and removal of micro-pollutants that are usually present in water. Also because of a significant amount of humic substances, which are often present in surface waters, more attention is focused on removing them. Due to their specific structure, they are characterized by high chemical activity and in natural waters they react with other substances, both organic and inorganic, which are present in water.

The tests, which were carried out, have shown that the amount of the reagent threshold dose is not only related to the physico-chemical properties of the suspension, but also depends on the concentration of the suspension. In order to conduct the coagulation process in an effective way, an appropriate amount (threshold dose) of coagulant is needed to be added to the suspension. The dependence determining the amount of the threshold dose and concentration can be described in the form of a mathematical function. For the tested suspension, this was a logarithmic function. Determination of the type of function describing the dependence of the threshold dose on the suspension concentration for the tested suspensions may contribute to practical use in laboratory tests as well as during the precise determination of the amount of coagulant needed for the coagulation process, when the concentration of suspension changes. 
The results from the research may contribute to the modelling and designing of highperformance sedimentation devices used in phase separation processes. Various separation techniques can be used to mechanically remove the solid phase. One of those techniques is the sedimentation process, often assisted by multiflux lamella packets in order to intensify the separation process [16] and also by the means of coagulation or flocculation process, which allow the solid-phase particles to aggregate into larger flocs [8] and thus produce clear water without the solid phase.

The coagulants used in the industry and water treatment stations will affect the sedimentation efficiency in various ways and should be selected individually for the treated suspension and should include the concentration of the suspension, because it has a great influence on the coagulation process. This parameter is often used in determining other indicators characterizing properties of suspensions such as sedimentation rate or efficiency [10], turbidity [17], and for modelling of flow processes [12]. In addition, reducing the reagent amount used for the process will potentially contribute to the cost reduction of the volume coagulation process.

The results also indicate that the sedimentation process is greatly affected by the concentration of the sedimenting material and its phase composition, and particle size distribution. Soil structures composed of clay materials and silica, often form agglomerates - it occurs as a result of fixed charges on the packets of clay minerals. These agglomerates can be difficult to sediment [18]. That is why it is important to use the coagulation process in order to obtain faster sedimenting particles. In addition, the use of multiflux sedimentation and coagulation could increases the effects of clarification process. Achieving this goal depends on many factors, such as: suspension concentration, the angle of the multiflux lamella packets, the coagulant dose and the type of suspension. Each of the above elements can have a significant impact on the final effect of the sedimentation process, which was presented in this article.

\section{References}

1. Główny Urząd Statystyczny, (Ochrona Środowiska 2015. Warszawa: Zakład Wydawnictw Statystycznych, 2015)

2. „Rozporządzenie Ministra Zdrowia z dnia 7 grudnia 2017 r. w sprawie jakości wody przeznaczonej do spożycia przez ludzi, Dz.U. 2017 poz. 2294.” .

3. World Health Organization, (Guidelines for Drinking-water Quality, 3. wyd. Geneva, 2008)

4. M. Banaś, T. Turlej, E. Wisła - Walsh, i B. Hilger, (The identification of selected properties of clay suspensions potentially used as source for water treatment plants", w Ecology, economics, education and legislation, Conference proceedings, SGEM 2015, Albena, Bulgaria, , t. 1, ,891-8972015)

5. W. Kowalski, M. Banaś, K. Kołodziejczyk, R. Mięso, i T. Zacharz, (The application of lamella sedimentation devices in purifying of water and water wastes. Kraków: UWND AGH, 2004)

6. W. P. Kowalski, M. Banaś, K. Kołodziejczyk, i T. Turlej, (Possibility of intensifying the sedimentation process of coal suspension by the use of synergic influence of multiflux sedimentation and flocculation, w Conference Proceedings. Vol. 2, Ecology and Environmental Protection, Albena, Bulgaria, t. 2, 515-5222014)

7. W. He, L. Xue, B. Gorczyca, J. Nan, i Z. Shi, (Comparative analysis on flocculation performance in unbaffled square stirred tanks with different height-to-width ratios: Experimental and CFD investigations, Chemical Engineering Research and Design, t. 132 , s. 518-535, kwi. 2018) 
8. M. Banaś, Przemysł Chemiczny, t. 96, nr 8, 1658-1661 (2017)

9. W. He, L. Xue, B. Gorczyca, J. Nan, i Z. Shi,(Experimental and CFD studies of floc growth dependence on baffle width in square stirred-tank reactors for flocculation, Separation and Purification Technology, t. 190, s. 228-242, sty. 2018)

10. M. Banaś, Przemyst Chemiczny, t. 95, nr 8, 1465-1468 (2016)

11. T. Turlej, W. Kowalski, M. Banaś, K. Kołodziejczyk, i P. Kohut, (An influence of concentration of coal suspension on the sedimentation rate of thickening process asissted by use of automated sedimentation test, w Conference Proceedings. Vol. 1, Ecology, Economics, Education and Legislation, Albena, Bulgaria, t. 1, 41-48.2015)

12. K. Kołodziejczyk, Przemyst Chemiczny, t. 95, nr 8, s. 1488-1491 (2016)

13. „PN-G-04570:1997. Przeróbka mechaniczna węgla kamiennego -Zawiesiny wodnomułowe -Oznaczanie prędkości osadzania części stałych.”

14. W. Kowalski $i$ in., (Modern sedimentation techniques in environmental protection. Kraków: Monografie Katedry Systemów Energetycznych i Urządzeń Ochrony Środowiska, 2015)

15. A. L. Kowal i M. Świderska-Bróz, (Oczyszczanie wody. Warszawa: Wydawnictwo Naukowe PWN, 1996)

16. M. Banaś, (Investigation of suspension concentration effects on sedimentation process. Kraków, 2003)

17. B. Hilger i P. Warzecha, Przemyst Chemiczny, t. 96, nr 8, 1677-1679 (2017)

18. Jianhua Du, Rada A. Pushkarova, i Roger St.C. Smart, Int. J. Miner. Process, 93, 66-72 (2009) 